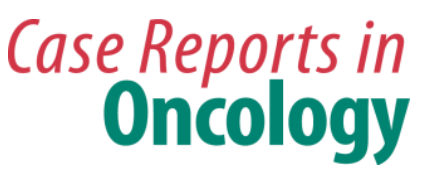

Case Rep Oncol 2017;10:508-514

DOI: $10.1159 / 000477489$

Publisnea onine. June 14, 2017

(c) 2017 The Author(s)

Published by S. Karger AG, Basel

www.karger.com/cro

This article is licensed under the Creative Commons Attribution-NonCommercial 4.0 International License (CC BY-NC) (http://www.karger.com/Services/OpenAccessLicense).

Usage and distribution for commercial purposes requires written permission.

\title{
Primary Type3 (Non-ABC, Non-GCB) Subtype of Extranodal Diffuse Large B-Cell Lymphoma of the Thyroid Bearing No MYD88 Mutation by Padlock Probe Hybridization
}

\author{
Yukiko Nishi $^{\mathrm{a}}$ Riko Kitazawa ${ }^{\mathrm{a}, \mathrm{b}}$ Ryuma Haraguchi ${ }^{\mathrm{a}} \quad$ Ayaka Ouchi $^{\mathrm{a}, \mathrm{b}}$ \\ Yasuo Ueda ${ }^{a, b}$ Yuri Kamaoka ${ }^{a, b}$ Ken Yamamoto $^{c}$ Yasuhiko Todo $^{c}$ \\ Hiroaki Miyaoka $^{c}$ Sohei Kitazawa ${ }^{a}$ \\ ${ }^{a}$ Department of Molecular Pathology, Ehime University, Graduate School of \\ Medicine, Toon City, Japan; ${ }^{b}$ Division of Diagnostic Pathology, Ehime University Hospital, \\ Toon City, Japan; 'Saiseikai Matsuyama Hospital, Matsuyama City, Japan
}

\section{Keywords}

Primary extranodal malignant lymphoma - Diffuse large B-cell lymphoma - MYD88 gene mutation

\begin{abstract}
Primary extranodal malignant lymphoma of the thyroid is a rare entity composed of mostly neoplastic transformation of germinal center-like B cells (GCB) or memory B cells. Other Bcell-type malignancies arising primarily in the thyroid have rarely been described. Immunohistochemical examination of autopsied primary malignant lymphoma of the thyroid in an 83-year-old Japanese female revealed the presence of a non-GCB subtype of diffuse large Bcell lymphoma (DLBCL) without the typical codon 206 or 265 missense mutation of MYD88. The lack of the highly oncogenic MYD88 gene mutation, frequently observed in DLBCL of the activated $B$-cell $(A B C)$ subtype, and the detection of an extremely aggressive yet local clinical phenotype demonstrated that the present case was an exceptional entity of the type3 (non$G C B$ and non-ABC) subtype.


 Oncology}

\section{Introduction}

Primary lymphoma of the thyroid is a rare entity, representing approximately $1-2 \%$ of all extranodal lymphomas and $<2 \%$ of all thyroid malignancies $[1,2]$. Herein, we describe an autopsy case of thyroid diffuse large B-cell lymphoma (DLBCL) with nongerminal center-like B cells (non-GCB) harboring no MYD88 mutation.

\section{Case Presentation}

An 83-year-old Japanese female had been receiving regular outpatient treatment by a general physician for follow-up of hypothyroidism over the previous 10 years. A rapidly growing thyroidal mass and swelling of the thyroid gland causing severe dyspnea were noted 1 month before she was admitted to our hospital. While the size of the thyroid glands increased continuously, administration of antibiotics brought about temporal improvement of the symptom symptoms. Clinically, the condition was assumed to be thyroidal anaplastic carcinoma. The patient died of cardiopulmonary arrest on day 10 after admission; autopsy was carried out $2 \mathrm{~h}$ postmortem. The size of the thyroid tumor was $13 \times 13 \times 8 \mathrm{~cm}$ (Fig. 1a). Tumor cells infiltrated the trachea, esophagus (Fig. 1b), and the middle of the right lobe of the lung (Fig. 1c). The patient was compromised with stomach cancer comorbidity (Fig. 1d). Pathological diagnosis of the resected thyroid specimen revealed diffuse infiltration of round cells with scant cytoplasm (Fig. 1e). On the other hand, histological analysis of the coincidental stomach cancer revealed signet-ring cell carcinoma (Fig. 1f). Immunohistochemical examination of thyroid tissue disclosed cells positive for CD20 (Fig. 2a) and MUM1 (Fig. 2b), and negative for CAM5.2 (Fig. 2c), CD3 (Fig. 2d), Bcl-6 (Fig. 2e), and CD10 (Fig. 2f).

To determine whether the non-GCB type of DLBCL was activated B-cell like (ABC) or of type3 (non-GCB and non-ABC) [3], immunohistochemical analysis was conducted to check for the presence of the MYD88 mutation [4] in the lymphoma cells. DNA samples from 5-mmthick sections of formalin-fixed paraffin-embedded specimens were selectively prepared from microdissected lymphoma cells by the agarose-bead-mediated technique [5] and subjected to PCR. Since codons 206 and 265 are the 2 hot spots of somatic MYD88 mutations recurrently observed among specific subsets of B-cell malignancies, especially in the ABC type of DLBCL [4], 2 sets of primers were used for PCR to cover 2 genomic regions: sense, $5^{\prime}$ CCGTGGCCTTCTAGCCAAC-3' and antisense, 5'-GATGTCCTGCCTGGCACCTG-3' for codon 206; and sense, $5^{\prime}$-TCTCTCCAGGTGCCCATCAGA- ${ }^{\prime}$ and antisense, 5' -CAAGTACAAGGCAATGAAGAA- $3^{\prime}$ for codon 265 . PCR products were ligated and cloned into T vector and sequenced. No typical c.794T $>$ C mutation causing the p.L256P mutation (Fig. 3a) and c.618T $>$ A mutation causing p.S206S silent mutation were found in 12 independent clones (Fig. 3b). To confirm that MYD88 harbored no missense mutation, padlock probe hybridization was carried out, followed by hyperbranched rolling-circle amplification, as previously described [6]. For target DNA sequencing, 2 genomic regions were used: no mutation, TCTCCAGGTGCCCATCAGAAGCGACTGATCCCCATCAAGTACAAGGCAAT and c.794T $>$ C mutation causing p.L256P mutation, TCTCCAGGTGCCCATCAGAAGCGACCGATCCCCATCAAGTACAAGGCAAT. For the padlock probe, 2 genomic regions were used: wild type, GTCGCTTCTGATGGGCACCT....CTTGTACTTGATGGGGATCA and mutant type GTCGCTTCTGATGGGCACCT....CTTGTACTTGATGGGGATCG. In the positive control DLBCL case with known pL256P mutation, signals were detected in both the wild-type padlock probe (Fig. 3a) and the mutant-type padlock probe (Fig. 3b). In the present case, however, signals were detected in the wild-type padlock probe 


\section{Case Reports in Oncology}

(Fig. 3c) but not in the mutant-type padlock probe (Fig. 3d). The present case was therefore confirmed to harbor no missense mutation and was finally diagnosed as an exceptional entity of type3 (non-GCB and non-ABC) subtype of DLBCL.

\section{Discussion}

Compared with secondary lymphoma with systemic involvement, primary malignant lymphoma of the thyroid is a rare entity and is mostly secondary to chronic thyroiditis $[1,2]$. As other extranodal lymphomas, primary malignant lymphoma of the thyroid is classified on the basis of pathological subtypes, each with a different prognosis.

Among the fewer than 150 cases described in the literature to date, the GCB subtype of DLBCL is the most common [7]. While cases with DLBCL, accounting for up to $70 \%$ of all primary malignant lymphomas of the thyroid, are aggressive subtypes associated with a poor prognosis, those with mucosa-associated lymphoid tissue usually follow an indolent course [8].

Since the first report of the highly oncogenic MYD88 p.L265P mutation in the ABC subtype of DLBCL [4], L265P mutation has been recurrently detected in primary central nervous system lymphoma, in primary cutaneous leg-type DLBCL [9], and in Waldenstrom macroglobulinemia [10], indicating that MYD88 is 1 of the target genes of certain subsets of B-cell malignancies at an early stage of oncogenesis. In the present case, while immunohistochemical examination of the tissue specimens revealed the presence of the non-GCB subtype of DLBCL (CD10 [-], Bcl-6 [-], MUM1 [+], Fig. 2), genetic analysis by both PCR and in situ morphological analyses showed a lack of typical codon 206 or 265 missense mutation (Fig. 3). The present case was finally diagnosed as type3 (non-GCB and non-ABC), a subtype of DLBCL that may account for a characteristic clinical course of a rapidly growing tumor, locally aggressive, yet without systemic involvement of distant organs.

\section{Statement of Ethics}

All procedures followed were in accordance with the ethical standards of the Ethical Committee of the Ehime University Hospital on human experimentation and with the Helsinki Declaration of 1964 and later versions. Informed written consent was obtained from the patient's family for this study.

\section{Disclosure Statement}

All authors declare that they have no conflicts of interest to disclose. 
Nishi et al.: Primary Type3 (Non-ABC, Non-GCB) Subtype of Extranodal DLBCL of the Thyroid Bearing No MYD 88 Mutation by Padlock Probe Hybridization

\section{References}

1 Verma D, Puri V, Agarwal S, Bhaskar A: Primary thyroid lymphoma: a rare disease. J Cytol 2014;31:218220.

2 Stein SA, Wartofsky L: Primary thyroid lymphoma: a clinical review. J Clin Endocrinol Metab 2013;98:3131-3138.

-3 Hans CP, Weisenburger DD, Greiner TC, Gascoyne RD, Delabie J, Ott G, et al: Confirmation of the molecular classification of diffuse large B-cell lymphoma by immunohistochemistry using a tissue microarray. Blood 2004;103:275-282.

4 Ngo VN, Young RM, Schmitz R, Jhavar S, Xiao W, Lim KH, et al: Oncogenically active MYD88 mutations in human lymphoma. Nature 2011;470:115-119.

5 Nakagawa M, Kitazawa R, Kuwahara N, Yoshida K, Haraguchi R, Kitazawa S: Efficient Genetic analysis of microdissected samples by agarose-bead method: alterations of beta-catenin gene in fundic gland polyp and heterotopic gastric mucosa of duodenum. Acta histochemica et cytochemica 2013;46:19-24.

6 Nilsson M: Lock and roll: single-molecule genotyping in situ using padlock probes and rolling-circle amplification. Histochem Cell Biol 2006;126:159-164.

-7 Knief J, Gebauer N, Bernard V, Schemme J, Reddemann K, Gebauer J, et al: Oncogenic mutations and chromosomal aberrations in primary extranodal diffuse large B-cell lymphomas of the thyroid - a study of 21 cases. J Clin Endocrinol Metab 2015;100:754-762.

8 Oh SY, Kim WS, Kim JS, Kim SJ, Lee S, Lee DH, et al: Primary thyroid marginal zone B-cell lymphoma of the mucosa-associated lymphoid tissue type: clinical manifestation and outcome of a rare disease consortium for improving survival of lymphoma study. Acta Haematol 2012;127:100-104.

-9 Pham-Ledard A, Cappellen D, Martinez F, Vergier B, Beylot-Barry M, Merlio JP: MYD88 somatic mutation is a genetic feature of primary cutaneous diffuse large B-cell lymphoma, leg type. J Invest Dermatol 2012;132:2118-2120.

10 Treon SP, Xu L, Yang G, Zhou Y, Liu X, Cao Y, et al: MYD88 L265P somatic mutation in Waldenstrom's macroglobulinemia. N Engl J Med 2012;367:826-833. 


\section{Case Reports in Oncology}
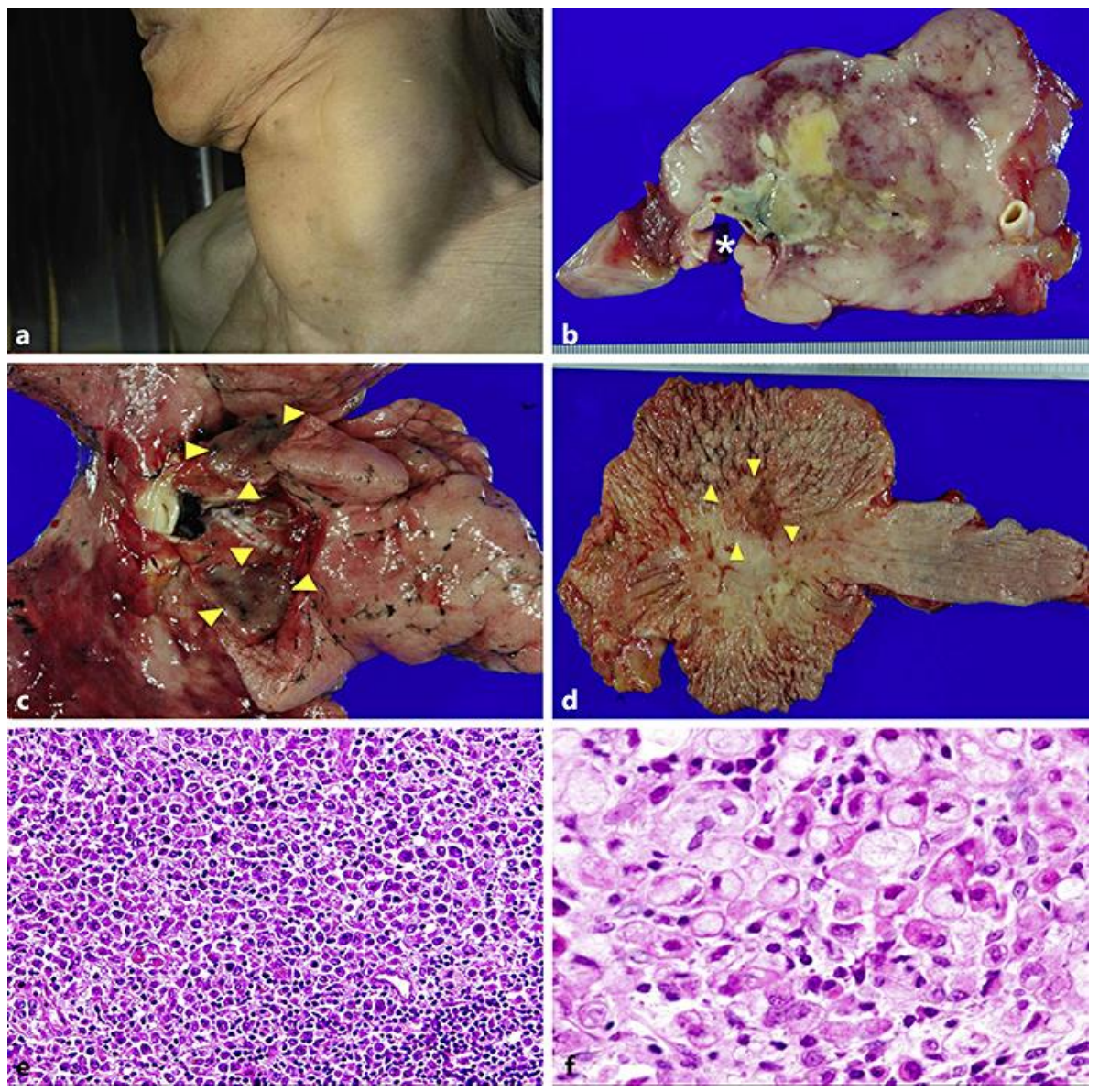

Fig. 1. a Enlarged thyroidal mass of $13 \times 13 \times 8 \mathrm{~cm}$ prominent at autopsy. The section of the cervix reveals a whitish, solid lesion with necrotic foci (b). Although systemic involvement was not observed, the tumor infiltrated the surrounding esophagus and the trachea (b, asterisk). c Infiltration of the 3-cm malignant lymphoma is also seen in the middle of the right lobe of the lung (arrowheads). $\mathbf{d}$ Coincidental finding of stomach cancer on the side of the lesser curvature of the body. e Histopathological analysis of the resected thyroidal tissue specimen, showing diffuse infiltration of the round cells with scant cytoplasm and a few atrophic and destroyed thyroid glands (HE. $\times 200$ ). On the other hand, the stomach cancer is a typical signet-ring cell carcinoma (f, HE. $\times 400)$. 


\section{Case Reports in Oncology}
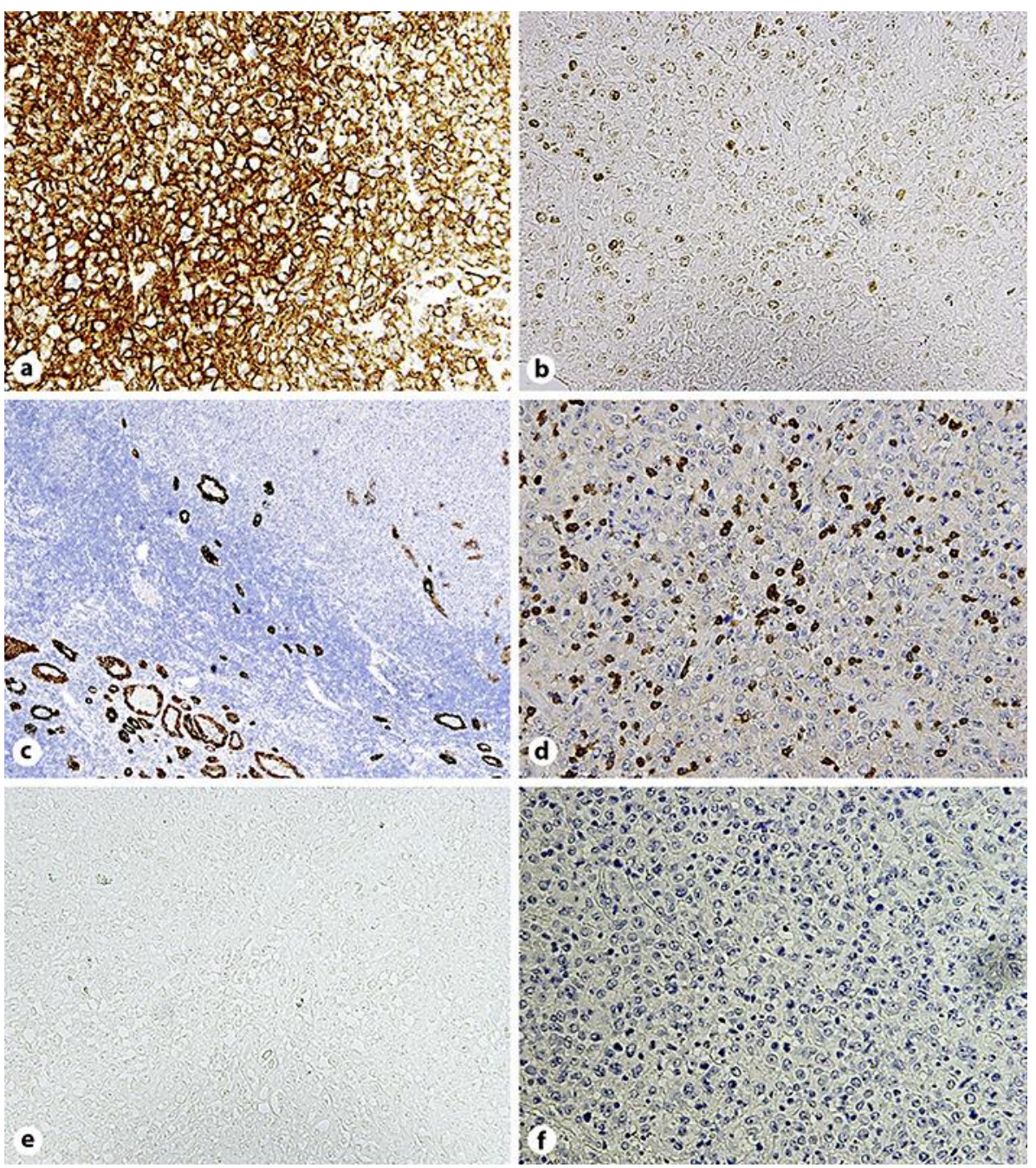

Fig. 2. a Immunohistochemical examination showing infiltrating cells positive for CD20 $(\times 200)$ and MUM1 (b, $\times 200)$ and negative for CAM5.2 (c, $\times 200)$, CD3 (d, $\times 200)$, Bcl-6 (e, $\times 200)$, and CD10 (f, $\times 200)$, confirming the diagnosis of nongerminal center-like B-cell type of diffuse large B-cell lymphoma. 


\section{Case Reports in Oncology}

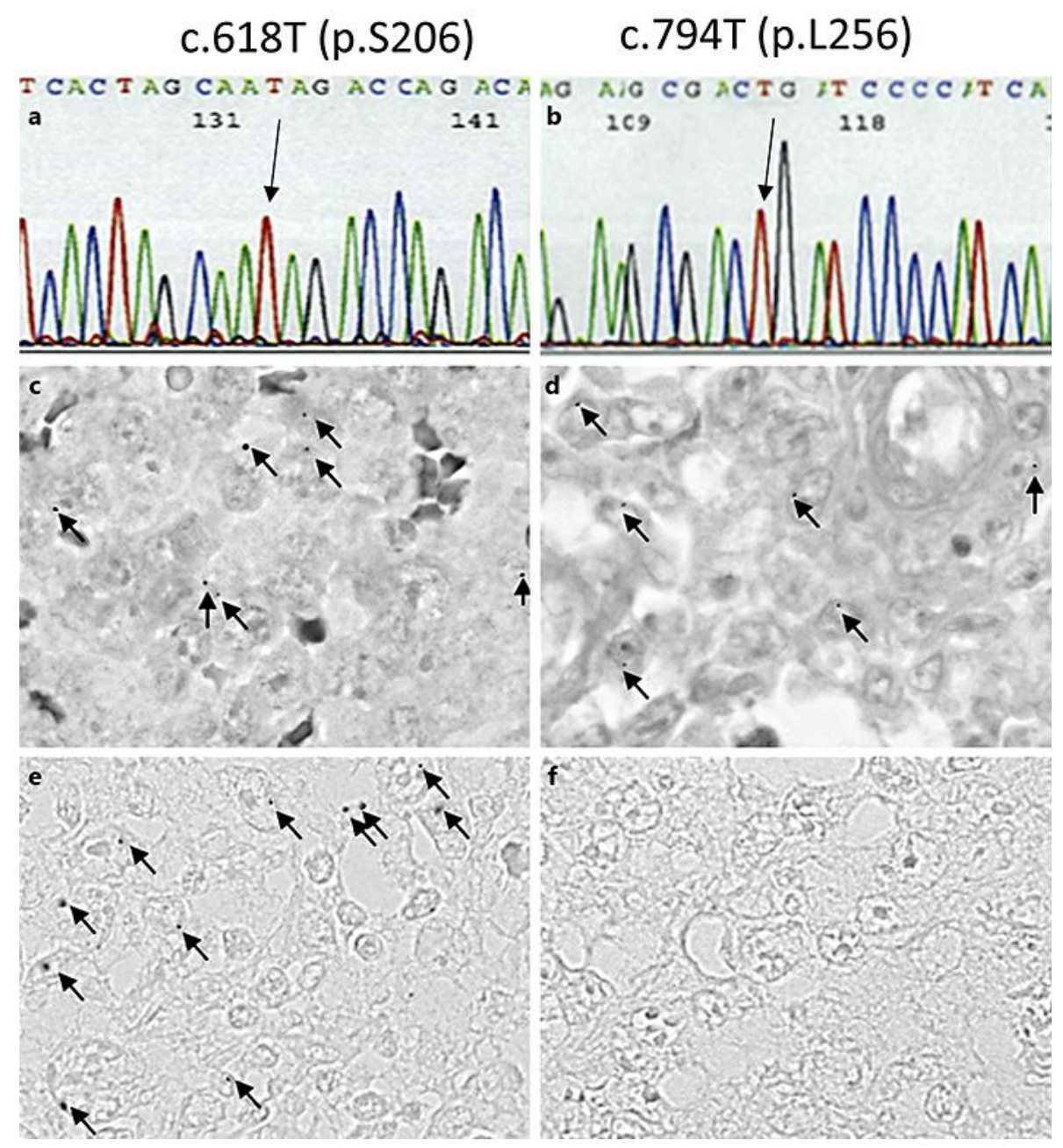

Fig. 3. PCR conducted with the use of formalin-fixed paraffin-embedded samples to explore a genetic alteration of the MYD88 gene. The PCR products were ligated and cloned into T vector and sequenced. No typical c.794T $>$ C mutation causing p.L256P mutation (a, arrow) or c.618T $>$ A mutation causing p.S206S mutation (b, arrow) is seen in 12 independent clones. Hyperbranched rolling-circle amplification was conducted to confirm PCR sequencing. In the positive control specimen from a diffuse large B-cell lymphoma case with a known typical c.974T>C mutation, signals are seen in both the wild-type padlock probe (a) and mutant-type padlock probe (b). In the present case, however, signals are seen in the wild-type padlock probe (c), but no signals are seen in the mutant-type padlock probe (d). 